\title{
Hydrogenation as an Aid in the Identification of Unsaturated Hydrocarbons by Gas Chromatography
}

\author{
BENGT SMITH and RAGNAR OHLSON
}

Institutionen för Organisk Kemi, Chalmers Tekniska Högskola, Göteborg, Sweden

\begin{abstract}
Methods are described for the hydrogenation of unsaturated hydrocarbon fractions obtained by condensation from analytical gas chromatographs. These hydrogenation methods make possible the identification of various unsaturated hydrocarbons on the basis of the retention times of their hydrogenation products.
\end{abstract}

$\mathrm{T}^{\mathrm{h}}$

The identification of unsaturated hydrocarbons by gas chromatography is mainly based on the determination of retention times using various columns (cf. Ref ${ }^{1}$.). This method is generally successful when applied to alkenes boiling in the range below $100^{\circ}$ in which case retention times for the majority of the compounds on a number of columns are well known ${ }^{1}$. However, in the case of higher boiling alkenes and for other types of unsaturated hydrocarbons, e.g. alkadienes and alkynes, the situation is less favourable since our knowledge about the retention times of these compounds is not so detailed. To complement the existing identification methods for unsaturated hydrocarbons, we have worked out some micro hydrogenation procedures which are applicable to the hydrogenation of such fractions as are obtained by condensation from analytical gas chromatographs using packed columns. The general principle of the method is to freeze out a compound or a mixture of compounds coming from the gas chromatograph and then hydrogenate the product partly or fully and, finally, re-run the hydrogenated product on a suitable column. From the chromatogram obtained, conclusions may be drawn concerning the nature of the compounds present in the original mixture. The advantage of the method is that compounds, the retention times of which are unknown, can be converted to compounds with known retention times, e.g. alkenes to alkanes, alkadienes to alkenes and alkanes, and alkynes to alkenes and alkanes. In addition compounds which cannot be separated on existing stationary phases may be converted by hydrogenation to separable products. 


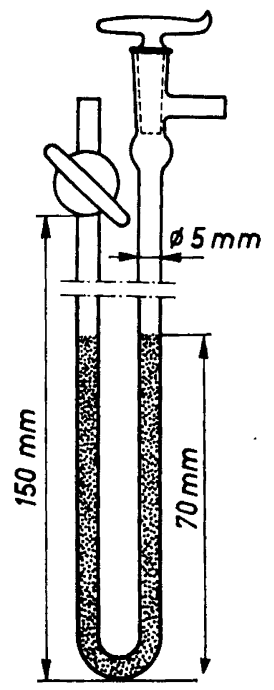

Fig. 1. U-Tube used in the hydrogenation experiments.

\section{HYDROGENATION PROCEDURES}

The procedures used in the full and stepwise hydrogenations of unsaturated hydrocarbons will be described in the following.

Procedure for the full hydrogenation of unsaturated hydrocarbons. A mixture of platinum dioxide (Adams catalyst ${ }^{2}$ ) and iron filings contaning about 1 wt. $\%$ of the oxide was used as hydrogenation catalyst. The iron filings acted as carriers for the platinum dioxide but they were also used because of their good heat conduction properties which facilitated the condensation of hydrocarbons from the gas stream coming from the chromatograph*. The iron filings-platinum dioxide mixture was filled into a U-tube (see Fig. 1) and the tube was immersed in a dry ice-acetone cooling bath and connected to the outlet of the chromatograph. In this way, the fraction of interest was condensed in the U-tube.

The tube was disconnected from the chromatograph and removed from the cooling bath. One side of the tube was closed and the other connected to a hydrogen container. Hydrogen was blown into the tube at such a rate that the pressure was raised to $3 \mathrm{~kg} /$ $\mathrm{cm}^{2}$ during about $1 \mathrm{~min}$. The tap on the tube was closed and the tube was removed from the hydrogen container and immersed in hot water $\left(80-90^{\circ} \mathrm{C}\right)$ for $10 \mathrm{~min}$. It was then connected to the gas inlet of the chromatograph (Perkin-Elmer Vapor Fractometer Model 154) and the hydrogenated products transferred to the chromatograph. Helium was generally used as the carrier gas. In the case of low boling hydrocarbons, however, it was sometimes necessary to use hydrogen instead since the large peak produced by the hydrogen in the U-tube, using helium as the carrier gas, tended to obscure compounds with short retention times. The same U-tube could be used without repacking for a considerable number of times **.

Procedure for the stepwise hydrogenation of alkadienes. The hydrogenation catalyst and equipment was the same as before but the conditions were changed. Thus, after the condensation of the hydrocarbon fraction in the U-tube, the latter was not removed

* Certain samples of iron filings were found to promote hydrogenation also in the absence of platinum dioxide.

** Care should be exercised in the hydrogenation procedure because of the ignition hazards connected with dry Adam's catalyst. Air must not be allowed to enter the hydrogenation tube. 
from the cooling bath but allowed to remain there during the filling of the tube with hydrogen.

The tube was removed from the cooling bath and shaken for a few seconds in order to mix the hydrocarbon fraction with the catalyst and then replaced in the bath. The tube was then connected to the gas inlet of the chromatograph, the cooling bath was exchanged for a beaker containing hot water $\left(80-90^{\circ} \mathrm{C}\right)$ and, after $5-10$ sec, the contents in the U-tube were blown into the chromatograph. The hydrogenation takes place almost entirely during the short time in the heating bath. It was namely found that, if the hydrogen in the U-tube was exchanged for helium before the heating, almost no hydrogenated products were formed.

Procedures for the stepwise hydrogenation of alkynes. $\mathrm{M}$ et $\mathrm{h}$ o d 1 . This method was identical to that described for the full hydrogenation of unsaturated hydrocarbons with the exception that the hydrogenation was performed at room temperature for $1 \mathrm{~min}$.

Table 1. Hydrogenation of dienes.

\begin{tabular}{|c|c|c|c|}
\hline \multirow[b]{2}{*}{ Compound } & \multirow{2}{*}{$\begin{array}{l}\text { Unchanged } \\
(\text { wt \%*) }\end{array}$} & \multicolumn{2}{|c|}{ Hydrogenation products (wt \%*) } \\
\hline & & Partly hydrogenated & Fully hydrogenated \\
\hline 1,3-Butadiene & 82 & $\begin{array}{l}\text { 1-Butene (6) } \\
\text { cis-2-Butene (1) } \\
\text { trans-2-Butene (2) }\end{array}$ & $n$-Butane (9) \\
\hline 1,4-Pentadiene & 75 & 1-Pentene (9) & $n$-Pentane (16) \\
\hline 1, cis-3-Pentadiene & 21 & $\begin{array}{l}\text { 1-Pentene (4) } \\
\text { cis-2-Pentene (10) } \\
\text { trans-2-Pentene ( } 7)\end{array}$ & $n$-Pentane (58) \\
\hline 1,trans-3-Pentadiene & 9 & $\begin{array}{l}\text { 1.Pentene (4) } \\
\text { cis-2-Pentene (3) } \\
\text { trans-2-Pentene (6) }\end{array}$ & n-Pentane (78) \\
\hline 1,2-Pentadiene & 98 & $\begin{array}{l}\text { 1-Pentene }(0.3) \\
\text { cis-2-Pentene (0.6) } \\
\text { trans-2-Pentene }(0.1)\end{array}$ & $n$-Pentane (1) \\
\hline 1,5-Hexadiene & 68 & 1-Hexene (11) & $n$-Hexane (21) \\
\hline cis-2,trans-4-Hexadiene & 22 & $\begin{array}{l}\text { cis-2-Hexene (8) } \\
\text { trans-2-Hexene (14) } \\
\text { cis-3-Hexene (3) } \\
\text { trans-3-Hexene (6) }\end{array}$ & $n$-Hexane (47) \\
\hline trans-2, trans-4-Hexadiene & 15 & $\begin{array}{l}\text { cis-2-Hexene (2) } \\
\text { trans-2-Hexene (14) } \\
\text { cis-3-Hexene (3) } \\
\text { trans-3-Hexene (6) }\end{array}$ & $n$-Hexane $(60)$ \\
\hline 1,trans-3-Hexadiene & 70 & $\begin{array}{l}\text { cis-2-Hexene (2) } \\
\text { trans-2-Hexene (5) } \\
\text { trans-3-Hexene (3) }\end{array}$ & $n$-Hexane (20) \\
\hline 1,3-Cyclopentadiene & 79 & Cyclopentene (8) & Cyclopentane (13) \\
\hline
\end{tabular}

* These values are only approximate since they were obtained by the internal normalization method putting percentage area equal to the weight per cent.

Acta Chem. Scand. 14 (1960) No. 6 
Method 2 utilized metallic sodium covered by a layer of sodium amide ${ }^{8,4} \mathbf{a s}$ catalyst and source of hydrogen*. A thread of sodium was pressed and transferred to the U-tube in a nitrogen atmosphere. Gaseous ammonia was then passed through the tube in order to form a layer of sodium amide on the surface of the sodium thread. After the condensation of the sample the tube was closed and left for 2 min at room temperature.

Material. The unsaturated hydrocarbons collected in Tables 1 and 2 were prepared in this laboratory. The synthesis of certain of these compounds as well as their retention values on various columns will be published elsewhere.

\section{RESULTS and DISCUSSION}

Full hydrogenation of unsaturated hydrocarbons. The hydrogenation procedure previously described was applied to a considerable number of straight chain and cyclic unsaturated hydrocarbons containing double and triple bonds. In all cases, a nearly $100 \%$ conversion to the corresponding saturated hydrocarbons was obtained. No partly hydrogenated products, e.g. alkenes from alkadienes and alkynes, were formed. Among the saturated cyclic hydrocarbons, only cyclopropanes reacted, yielding paraffins. Aromatic hydrocarbons were converted to cyclohexanes with a yield generally exceeding $90 \%$.

Stepwise hydrogenation of alkadienes. It turned out to be a difficult task to stop the hydrogenation of an alkadiene at the alkene stage. Several attempts at room temperature, using poisoned platinum dioxide and other less active catalysts, failed. The technique described in the experimental part, however, made possible the conversion of a sufficient amount of a diene to the corresponding monounsaturated hydrocarbons. Some typical results of the hydrogenation of a number of straight chain and cyclic dienes are given in Table 1.

In most instances, the expected hydrogenation products were formed. Thus, there was obtained 1-butene from 1,3-butadiene as the results of 1,2addition, and cis- and trans-2-butene as the result of 1,4-addition. Naturally, the fully hydrogenated product, $n$-butane, was also formed. There was a marked difference in reactivity between various dienes, 1, trans-3-pentadiene being especially reactive. In this case, it was necessary to shorten the hydrogenation time in order to get enough of the alkenes. The two 1,3-pentadienes gave the same hydrogenation products. It was, however, still possible to distinguish between the two isomers on the basis of the proportions between cis- and trans-2-pentene. In the case of 1,cis-3-pentadiene, more cis-2-pentene than trans-2-pentene was formed. The cis isomer can be formed by 1,2-as well as 1,4-addition but the trans isomer only by 1,4-addition**. For 1, trans3-pentadiene, the reverse is true and more trans-2-pentene than cis-2-pentene was obtained. Although the further hydrogenation to $n$-pentane might change the original proportions between cis- and trans-2-pentene, the results have in numerous experiments always turned out to be in accordance with the theory.

1,2-Pentadiene was the only diene of allene type investigated here. It was found to be considerably more resistent to hydrogenation than dienes with

\footnotetext{
* Concerning the use of sodium alone as catalyst, cf. p. 1322.

** Concerning the possibilities of a cis-trans isomerization during the hydrogenation, cf. below.
} 
Fig. 2. Hydrogenation of 1,3-butadiene. Column, dimethylsulpholane $(20 \%)$ on Chromosorb 30-60 mesh, $3 \mathrm{~m}$. Temperature $25^{\circ} \mathrm{C}$. Flow of $\mathrm{He} 25 \mathrm{ml} / \mathrm{min}$. Recorder attenuation as denoted.

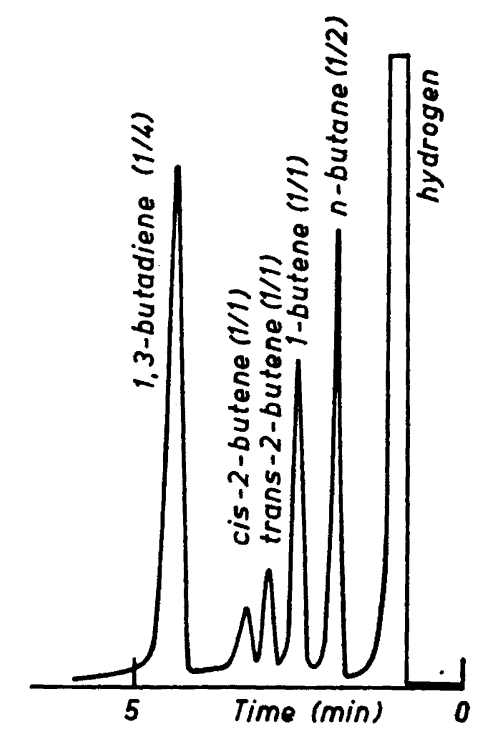

conjugated and isolated double bonds. Thus, only $2 \%$ of it was converted. This difference in reactivity makes it easy to distinguish between 1,2-pentadiene and the two 1,3-pentadienes by partial hydrogenation although the same hydrogenation products are formed.

The results of the hydrogenation of the two 2,4-hexadienes are noteworthy. From cis-2,trans-4-hexadiene, the expected hydrogenation products were formed. The same hydrogenation products, however, were obtained in the case of trans-2,trans-4-hexadiene, the formation of cis-2-hexene being unexpected. Since we believe that the experimental conditions excluded any contamination from other compounds, we are forced to assume that an isomerization takes place during the hydrogenation. Neither in this case nor in several other cases investigated did any isomerization occur in the absence of hydrogen. Attempts to convert trans-2-hexene and trans-3-hexene to their cis isomers using the method for the partial hydrogenation of alkadienes also failed. Thus, it must be concluded that a cis-trans isomerization can take place in certain instances under the experimental conditions used but the phenomenon does not seem to be a general one.

We are not aware of any previous reports on catalytic cis-trans conversions of ethylenic hydrocarbons although the corresponding thermal reaction has been studied ${ }^{5}$. Catalytic isomerization of dimethyl maleate on hydrogenation catalysts, however, has been observed ${ }^{6}$.

One proposed mechanism ${ }^{7}$ for the hydrogenation of ethylenic double bonds on metal catalysts involves a reaction between a chemisorbed alkene molecule and hydrogen to form a chemisorbed alkyl radical which is then further hydrogenated to an alkane during the second step. Since the first step is reversible, the possibility of a cis-trans isomerization obviously exists. 
Table 2. Hydrogenation of alkynes.

\begin{tabular}{|c|c|c|c|c|}
\hline \multirow{2}{*}{ Compound } & \multirow{2}{*}{ Catalyst } & \multirow{2}{*}{$\begin{array}{l}\text { Unchanged } \\
\left(\text { wt } \%^{*}\right)\end{array}$} & \multicolumn{2}{|c|}{ Hydrogenation products (wt \%*) } \\
\hline & & & $\begin{array}{c}\text { Partly } \\
\text { hydrogenated }\end{array}$ & $\begin{array}{c}\text { Fully } \\
\text { hydrogenated }\end{array}$ \\
\hline \multirow{2}{*}{ 3-Hexy ne } & $\mathrm{PtO}_{2}(\operatorname{method} 1)$ & 50 & $\begin{array}{l}\text { cis-3-Hexene (15) } \\
\text { trans-3-Hexene (3) }\end{array}$ & $n$-Hexane (32) \\
\hline & $\mathrm{NaNH}_{2}(\operatorname{method} 2)$ & 90 & trans-3-Hexene (10) & 0 \\
\hline \multirow{2}{*}{ 2-Hexyne } & $\mathrm{PtO}_{2}(\operatorname{method} 1)$ & 55 & $\begin{array}{l}\text { cis-2-Hexene (10) } \\
\text { trans-2-Hexene (2) }\end{array}$ & $n$-Hexane (33) \\
\hline & $\mathrm{NaNH}_{2}$ (method 2) & 60 & trans-2-Hexene (40) & $n$-Hexane (trace) \\
\hline \multirow{2}{*}{ 1-Hexyne } & $\mathrm{PtO}_{2}^{* *}$ & 96 & 1-Hexene (3) & $n$-Hexane (1) \\
\hline & $\begin{array}{l}\mathrm{NaNH}_{2}(\operatorname{method} 2) \\
\mathrm{Na}(\operatorname{method} 2)\end{array}$ & $\begin{array}{l}38 \\
37\end{array}$ & $\begin{array}{l}\text { 1-Hexene (62) } \\
\text { 1-Hexene (63) }\end{array}$ & $\begin{array}{l}0 \\
0\end{array}$ \\
\hline
\end{tabular}

* Cf. note under Table 1 .

** The method used for the partial hydrogenation of alkadienes was applied.

It is known that migration of a double bond may occur in the presence of hydrogenation catalysts ${ }^{8-11}$. There are, however, no indications in our experimental material that such a migration takes place under the conditions used for the partial hydrogenation of dienes.

The chromatogram obtained after the hydrogenation of 1,3-butadiene is shown in Fig. 2.

Stepwise hydrogenation of alkynes. Some results from the stepwise hydrogenation of alkynes are given in Table 2. Hydrogenation over platinum dioxide mainly produced alkanes and cis alkenes in those instances where two stereoisomeric forms of the alkene were present. This result is in accordance with previous experience ${ }^{12}$. There are no signs of a double bond migration taking place during the hydrogenation (cf. above). Hydrogenation in the presence of sodium amide was quite stereospecific, the trans alkene being formed only. A possible mechanism for this reaction has been proposed by Raphael ${ }^{13}$. In the hydrogenation of 1-hexyne using method 2, it was found that sodium alone was as effective a catalyst as sodium covered with a layer of sodium amide. In this case hydrogen is furnished in the reaction between 1-hexyne and sodium. No hydrogenation took place when 3-hexyne was treated in the same way, since no hydrogen is formed. It seems possible to identify a triple bond in 1-position by this method.

Sodium amide is said not to promote the hydrogenation of an alkene to the corresponding alkane. We have, however, repeatedly obtained small amounts of $n$-hexane in the hydrogenation of 2 -hexyne. It may be that small amounts of impurities in the sodium, e.g. traces of metal from the sodium press, are responsible for this conversion. 
Fig. 3. Hydrogenation of 1-hexyne. Column, $\beta, \beta^{\prime}$-oxydipropionitrile $(20 \%)$ on Chromosorb $30-60$ mesh, $2 \mathrm{~m}$. Temperature $25^{\circ} \mathrm{C}$. Flow of $\mathrm{He} 50 \mathrm{ml} / \mathrm{min}$. Recorder attenuation as denoted.

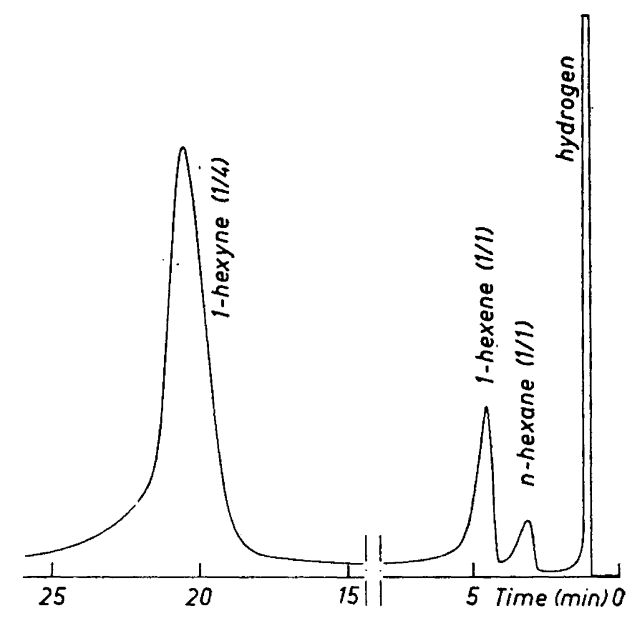

The results of the hydrogenation of 1-hexyne using the method for the partial hydrogenation of alkadienes illustrate the small conversion of an alkyne under these conditions (cf. 1,5-hexadiene in Table 1).

It is not possible to hydrogenate dienes to alkenes by any of the methods used for the hydrogenation of alkynes. The first method only produces saturated hydrocarbons and, with the last two, the dienes remain unchanged apart from the possible formation of traces of monounsaturated and saturated products. The chromatogram obtained after the hydrogenation of 1-hexyne over platinum dioxide is shown in Fig. 3.

Use of the hydrogenation methods. The examples given above demonstrate the application of the hydrogenation methods to the identification of unsaturated hydrocarbons. The methods are especially useful in the case of dienes and alkynes and, in many instances, permit a simple and straightforward identification of these hydrocarbons. They are also valuable for deciding whether a band on the chromatogram contains unsaturated hydrocarbons or not and for the conversion of unseparable, unsaturated hydrocarbons to separable, saturated ones. Thus, in the qualitative and quantitative analysis of mixtures of 3- and 4-methyl-1-pentene which until recently ${ }^{14}$ could not be separated on any stationary phase known, we hydrogenated the mixture to 2-and 3-methylpentane which could easily be separated on, for example, squalane.

Acknowledgement. This work was supported by grants from the Swedish Technical Research Council and the Town Council of Gothenburg.

\section{REFERENCES}

1. Knight, H. S. Anal. Chem. 30 (1958) 9.

2. Voorhees, V. and Adams, R. J. Am. Chem. Soc. 44 (1922) 1297. See also Org. Syntheses, Coll. Vol. 1, (1932) 452.

3. Campbell, K. N. and Eby, L. T. J. Am. Chem. Soc. 63 (1941) 2684.

Acta Chem. Scand. 14 (1960) No. 6 
4. Henne, A. L. and Greenlee, K. W. J. Am. Chem. Soc. 65 (1943) 2022.

5. Kistiakowsky, G. B. and Smith, W. R. J. Am. Chem. Soc. 56 (1934) 638; 58 (1936) 766.

6. Freudenberg, K. Stereochemie, Franz Deuticke, Leipzig and Wien 1933, p. 918.

7. Twigg, G. H. in Heterogeneous Catalysis, Discussions of the Faraday Society 8 (1950) 152.

8. Twigg, G. H. Proc. Roy. Soc. London, Ser. A 178 (1941) 106.

9. Taylor, T. J. and Dibeler, V. H. J. Phys. \& Colloid Chem. 55 (1951) 1036, 1065.

10. Zelinsky, N. D. and Levina, R. J. Ber. 62 (1929) 1861.

11. Richter, F. and Wolf, W. Ber. 59 (1926) 1733.

12. Raphael, R. A. Acetylenic Compounds in Organic Synthesis, Butterworths Scientific Publications, London 1955, p. 24.

13. Ref. 12, p. 27.

14. Smith, B. and Ohlson, R. Acta Chem. Scand. 13 (1959) 1253.

Received March 24, 1960. 